\title{
PSICOLOGIA, LITERATURA E SAÚDE MENTAL $^{1}$
}

\section{PSYCHOLOGY, LITERATURE AND MENTAL HEALTH}

\author{
Luan Felipe de Souza Junqueira* \\ https://orcid.org/0000-0002-3520-6338 \\ USP
}

\author{
Fabio Scorsolini-Comin ${ }^{* *}$ \\ https://orcid.org/0000-0001-6281-3371. \\ USP
}

\begin{abstract}
Resumo: As relações entre Psicologia e literatura têm sido discutidas nos meios acadêmicos, sobretudo a partir de um interesse em problematizar como o humano pode ser descrito e compreendido, não como se fosse um objeto exclusivo de um dado campo, mas como um elemento capaz de produzir reflexões que atravessam áreas, o que deveria promover como efeito a sua aproximação e não o seu afastamento, como observamos na ciência contemporânea e na própria formação em saúde. A partir dessa lacuna, o objetivo deste estudo teórico foi refletir sobre as possíveis aproximações entre Psicologia e literatura, tendo como campo de aplicação a saúde mental. O referencial adotado para tal reflexão foi o da psicanálise, especialmente a partir das contribuições do psicanalista inglês D. W. Winnicott. Com base em conceitos disparadores, como os de identificação, objeto transicional e o brincar, problematizamos como a leitura, a escrita e o contato com a literatura podem ser ferramentas terapêuticas potentes para o amadurecimento emocional. No campo da formação em saúde, em que pese o distanciamento dos profissionais de áreas como a literatura, recomendamos que a retomada desse contato pode ser importante no sentido da promoção de um cuidado mais humanizado.
\end{abstract}

Palavras-chave: Literatura. Psicologia. Psicanálise. Saúde mental.

\begin{abstract}
The relations between Psychology and literature have been discussed in academic circles, above all from an interest in problematizing how human can be described and understood not as if it were an exclusive object of a given field, but as an element capable of producing reflections
\end{abstract}

\footnotetext{
${ }^{1} \mathrm{O}$ presente estudo recebeu apoio da Coordenação de Aperfeiçoamento de Pessoal de Nível Superior (Capes), por meio de bolsa de Mestrado ao primeiro autor, sob orientação do segundo.

* Psicólogo. Mestre em Ciências pelo Programa de Pós-Graduação em Enfermagem Psiquiátrica da Escola de Enfermagem de Ribeirão Preto da Universidade de São Paulo (USP). E-mail: <luan.f.junqueira@gmail.com>.

** Psicólogo, Mestre, Doutor e Livre Docente em Psicologia pela Universidade de São Paulo (USP). Professor do Programa de Pós-Graduação em Enfermagem Psiquiátrica e do Programa de Doutorado Interunidades da Escola de Enfermagem de Ribeirão Preto da USP. Bolsista de Produtividade em Pesquisa do Conselho Nacional de Desenvolvimento Científico e Tecnológico (CNPq). E-mail: <fabio.scorsolini@usp.br>.
} 
that cross areas, which should promote the effect of bringing them together and not moving away, as we observed in contemporary science and in health training itself. From this gap, the objective of this theoretical study is to reflect on the possible approximations between Psychology and literature, having mental health as its field of application. The framework adopted for this reflection is that of Psychoanalysis, mainly based on the contributions of the English psychoanalyst D. W. Winnicott. From triggering concepts such as identification, transitional object and playing, we problematize how reading, writing and contact with literature can be powerful therapeutic tools for emotional maturation. In the field of health education, despite the distance from professionals in areas such as literature, we recommend that the resumption of this contact may be important in the sense of promoting more humanized care.

Keywords: Literature. Psychology. Psychoanalysis. Mental health.

\section{Introdução}

Para algumas áreas das Ciências da Saúde a relação com a literatura pode parecer um tanto estranha ou distante, principalmente naquelas consideradas mais “tradicionais” ou que se ocupam de um cuidado “concreto” sobre o corpo e suas funções. A saúde e a literatura, nessa acepção, seriam dimensões imiscíveis, com cada área do saber produzindo inteligibilidades que, a priori, não poderiam e nem deveriam se encontrar.

Nesse ponto, a Psicologia estaria em uma posição privilegiada, pois encontra-se muito próxima da fronteira entre as Ciências da Saúde e das Ciências Humanas. Para alguns autores, a Psicologia e a literatura poderiam ser consideradas até mesmo interdisciplinares, ou melhor, fariam parte de um campo do saber em que existiria uma grande possibilidade de convergência e interlocução de ideias e elementos para o entendimento de fenômeno, como o contato entre as pessoas, o apreço por suas histórias sempre muito particulares, o treino dos sentidos para apreensão de detalhes importantes, entre outros (SANTOS; SANTOS; SILVA, 2018).

Extrapolando tal assertiva, Oguisso e Silva (2017), no domínio da História da Enfermagem, apoiam-se na ideia de que não só é possível fazer aproximações entre a arte do cuidado e a arte propriamente dita, nesse caso a literária, mas devendo ser tratado como algo quase natural, em que para ambas são muito próximas, se não até mesmo semelhantes, envolvendo a necessidade de ter-se atenção, delicadeza e sutileza para adentrar o interior de um outro. No entanto, ainda segundo essas autoras, as Ciências da Saúde, de um modo amplo, pouco se comprometeriam em transformar suas vivências em saber literário, atendo-se principalmente à literatura científica, seja consumindo-a, seja produzindo-a.

Contudo, Oguisso e Silva (2017) destacam que a literatura científica não teria a condição de transmitir sentimentos, sensações e emoções da mesma forma que textos literários, defendendo a ideia de que os profissionais da saúde deveriam ocupar-se, também, da arte literária, tanto lendo como escrevendo. Para as autoras, a literatura e a escrita, seja de poemas, contos, crônicas, romances, entre outros, trariam benefícios para os próprios profissionais da saúde, uma vez que constantemente estes se veem profundamente envolvidos emocionalmente com 
aquelas pessoas para as quais prestam cuidados e, não raro, se comovem, choram, sentem dor e vibram a cada conquista ou melhora. Aqui podemos depreender um dos primeiros sentidos da literatura no campo das Ciências da Saúde: como espaço de expressão, de endereçamento, de escuta e de acolhimento.

Obviamente que esse sentido se distancia muito do saber biomédico, promovendo o estranhamento de muitos estudantes e profissionais da saúde ao se depararem com a possibilidade desse diálogo. A Psicologia, por sua vez, encontra-se comprometida de modo mais evidente com essa interlocução. As relações entre Psicologia e literatura têm sido discutidas nos meios acadêmicos, sobretudo a partir de um interesse em problematizar como o humano pode ser descrito e compreendido, não como se fosse um objeto exclusivo de um dado campo, mas como um elemento capaz de produzir reflexões que atravessam áreas, o que deveria promover como efeito a sua aproximação e não o seu afastamento, como observamos na ciência contemporânea e na própria formação em saúde (SCORSOLINI-COMIN; FIGUEIREDO, 2018; SCORSOLINI-COMIN; SANTOS, 2012).

A partir dessas reflexões, podemos compreender o envolvimento com a literatura como uma possibilidade de cuidado de si e do outro, o que pode ter diferentes endereçamentos quando pensamos o campo da saúde mental, os recursos produzidos em saúde e, também, a humanização do cuidar (SCORSOLINI-COMIN, 2019; SCORSOLINI-COMIN; SANTOS, 2010). Com base nessas considerações, o objetivo deste estudo teórico é refletir sobre as possíveis aproximações entre Psicologia e literatura, tendo como campo de aplicação a saúde mental. O referencial adotado para tal reflexão é o da psicanálise, principalmente a partir das contribuições do psicanalista inglês D. W. Winnicott.

\section{O processo criativo}

Há de considerarmos que a ciência e a arte, apesar de suas diferenças quanto à matéria da qual irão se ocupar, não são - ou não deveriam ser - elementos tão distantes entre si, mas deveriam ser tidas como complementares, pois cada uma, ao seu modo, busca uma apreensão do ser humano. Enquanto a ciência busca a compreensão em termos de leis gerais, constantes e replicáveis, a arte ocupa-se da singularidade, do particular, do sutil e do único. É reconhecer que a técnica e a tecnologia, sem a humanidade, são frias e vazias. Do mesmo modo, é possível considerarmos que determinados textos literários, para além de trazerem um profundo entendimento da alma humana, possuem, ao serem lidos, a condição de trazerem bem-estar e conforto psíquico, promovendo saúde mental, seja para quem escreve, seja para quem lê (OGUISSO; SILVA, 2017; SILVEIRA, 2018).

Em que pesem esses desfechos terapêuticos considerados positivos, decorrentes do envolvimento com a literatura, por meio de atividades de leitura e de escrita, é importante destacarmos que a literatura não se apresenta como algo utilitário, como um recurso ou como uma estratégia de enfrentamento que poderia ser empregada em um dado momento por parte do sujeito em sofrimento, bem como um elemento que poderia ser igualmente abandonado em momentos de maior estabilidade emocional. A literatura também pode promover o desconforto e a incompletude, permitindo ao sujeito entrar em contato com a falta, com a incerteza, com 
o desamparo, com aquilo que ainda não pode nomear. Ainda assim, a literatura cumpre uma função importante ao possibilitar a desautomatização da vida e o contato com sensações muitas vezes escamoteadas em uma sociedade comprometida com a busca desenfreada pelo prazer e pela satisfação dos desejos. Ao permitir o contato com esses outros elementos que também compõem o viver, a literatura pode conduzir a uma leitura mais visceral do cotidiano em todas as suas tonalidades.

Cabe pensarmos, portanto, como se dariam e quais seriam tais benefícios que a literatura pode nos proporcionar. Segundo Leite (1987), para a Psicologia estudar obras literárias deve ser levada em consideração uma série de características a respeito da obra, do escritor, do leitor e do envolvimento desses elementos. Ao fazer-se a intersecção entre Psicologia e literatura, é possível considerarmos três tipos de olhares “distintos” entre si, mas indissociáveis, pois dialogam constantemente, sendo eles: olhar para a obra literária, pensar a respeito dos processos criativos e mentais e utilizar a literatura de forma terapêutica.

Inicialmente, salientamos que, deste ponto em diante, neste estudo, será assumido um caráter psicanalítico no entendimento a respeito da relação e do impacto do contato entre a pessoa e a literatura/obra literária, principalmente pela estreita relação que a psicanálise assume com a literatura desde a sua origem em Freud. Para França (2014), a psicanálise é uma importante ferramenta para o entendimento e a interpretação de textos literários, pois tem a condição de lançar luz sobre questões da vida emocional que são significativas para o entendimento da intenção do autor, do desenvolvimento dos personagens e de características do leitor, ao pensar suas questões subjetivas que ressoam no contato com o texto por intermédio da sua visão e de seus conceitos.

Outra recomendação torna-se lícita nesse ponto. Como aponta Passos (2002), o diálogo entre psicanálise e literatura também deve ser estabelecido, considerando que a literatura não deve se propor a ilustrar patologias discutidas na ciência psicológica, por exemplo, como foi construído historicamente por estudiosos no início do século XX. Também a psicanálise deve escapar às chamadas “[...] soluções perigosas e cômodas, tais como diagnósticos, complexos, modelos identificatórios pré-estabelecidos, explicações e jargões” (PASSOS, 2002, p. 177) que, por vezes, costuram as relações entre esses dois campos. Assim, é fundamental que esse diálogo seja comprometido com o respeito às singularidades de cada área e às suas naturezas.

Azevedo (2019) destaca que a psicanálise sempre manteve um laço muito estreito com a literatura, já que Freud tinha obras literárias, escritores, poetas e filósofos como fontes de diálogo e de inspiração. Desse modo, o universo da arte estava diretamente oferecendo um contexto para a produção de suas ideias e de suas reflexões abarcadas nesse modo de pensar e refletir sobre o mundo, o ser humano e a condição humana. Ainda para Azevedo (2019), Freud teve muita sensibilidade em reconhecer, em obras literárias e na construção de seus personagens, a capacidade de descrição tão detalhada e aprofundada da "alma” humana e uma imensa felicidade em reivindicar para a psicanálise esse mesmo poder poético e intuitivo que observava. Há de destacarmos até mesmo uma certa “ousadia” por propor um olhar que fugia à ciência tradicional, sobretudo à época, final do século XIX.

Neste momento, cabe pensarmos na dinâmica existente no interior do leitor ao entrar em contato com obras literárias. É do humano, desde os seus primórdios, transmitir a outras pessoas o que sente e o que vive, como também é natural ao ser humano se beneficiar dessas comunicações para ter condições mais confortáveis de vida (MIYAGAWA; LESURE; NÓBREGA, 
2018). A criatividade em conseguir comunicar-se fez com que o homem se multiplicasse e se desenvolvesse. Santos, Santos e Silva (2018) destacam que, na antiguidade grega, em Platão e Aristóteles, entendia-se que o ato criativo seria uma atividade necessária ao ser humano para a representação da realidade, para transformar em "imagem” algo abstrato para que pudesse ser transmitido e pensado.

Da mesma forma, segundo Leite (1987), o processo criador tem a função de ajudar a elaborar soluções diante de problemas, em busca de uma maneira de resolvê-los. No caso de questões de ordem emocional ou psicológica (abstratos por natureza), uma solução criativa seria justamente as criações artísticas (neste caso, a literatura) que conseguem assumir o papel de expressar e transformar em "imagem” um pensamento de difícil representação. Por meio da linguagem, escrita ou falada, é que se dá forma ao que se sente.

A arte consegue dar voz ao que é interno, do mesmo modo que a psicanálise dirige o seu olhar na busca do que é mais íntimo, profundo. Assim, o diálogo entre arte e psicanálise sempre ocorreu. Segundo Leite (1987), devemos considerar, no entanto, que a obra literária, por si só, para além do seu reconhecido valor estético, é um objeto "neutro", pois não tem sozinha a capacidade de promover satisfação ou impactos emocionais, mas receberá o valor "positivo" ou “negativo” por inúmeros fatores, principalmente no que diz respeito ao leitor.

Para Leite (1987), há fatores objetivos como características do texto, o tema de interesse, a tensão intelectual necessária do leitor, como também há “níveis” de leitura sobre um mesmo material, desde uma mais superficial ou um "passatempo”, até uma leitura mais aprofundada, atendo-se às tensões dos personagens, motivações para as ações diante do desenvolvimento da trama. Do mesmo modo, o autor destaca que a percepção e a pré-disposição do leitor de entrar em contato com a obra e se ver envolvido, têm a capacidade de transformar algo "sem nenhum valor" em objetos que vão além e se tornam importantes, seja pela fase da vida ou estado afetivo-emocional. Isso faz com que o texto seja interessante para uns e não a outros e permite que se faça novas interpretações para a obra.

Na mesma linha, Santos, Santos e Silva (2018) apontam que a relação entre leitor e texto se trata de algo muito particular, uma vez que as obras literárias devem ser entendidas para além da necessidade de se desvendar uma mensagem oculta no texto, mas deve-se tratar de uma interlocução que seja capaz de causar algum efeito em quem lê. Por ser uma interlocução, parte-se do princípio de que há a necessidade de o leitor depositar algo de si no texto, o que leva a uma leitura única da obra.

\section{Um jogo de espelhos: a identificação do leitor com a obra literária}

França (2014) destaca que Freud entendia que uma das maiores contribuições da literatura é fazer com que o leitor possa identificar-se com as histórias e os personagens, reconhecendo neles suas próprias angústias, seus dramas, desejos inconscientes e conscientes. Para Freud (1996a), é possível identificar-se, mergulhar e reorganizar um mundo imaginativo enquanto se mantém na realidade. Isso faz com que haja um (re)conhecimento de si, e o sujeito se veja nos personagens, percebendo traços que são seus. Pode-se espelhar nesses personagens, portanto, para viver a sua própria jornada. 
É especialmente proveitoso falarmos em identificação quando discutimos sobre obras literárias, pois ela pode ser entendida, segundo Laplanche e Pontalis (2001), como um processo em que a pessoa assimila para si aspectos, propriedades, atributos, entre outros, de alguma outra coisa ou alguém. Podemos considerar que, nesse processo de identificação, há uma série de sentimentos, de ações e de processos mentais que a compõem, tais como a imitação, a empatia, o ver-se contagiado por outrem e a projeção. Por ser um processo, deve ser entendido como algo dinâmico, que vai acontecer por todo o tempo, durante toda a vida. Cabe considerarmos que as identificações que a pessoa faz ao longo da vida vão construindo e formando a sua personalidade (LAPLANCHE; PONTALIS, 2001).

Para acontecer esse jogo de identificações, devemos considerar algum grau de desenvolvimento psíquico, em que a pessoa já é capaz de reconhecer a existência de um outro que é separado e diferente dela. Nesse sentido, cumpre pensarmos nas contribuições feitas por Winnicott nessa relação, principalmente objeto/fenômeno transicional e espaço potencial. Resumidamente, no início da vida, o bebê vive uma ilusão de que ele é um com a mãe. Isso traz segurança para ele e o tranquiliza, sendo necessário nesse estágio. No entanto, gradativamente, à medida que vão acontecendo pequenas falhas e frustrações, esse bebê vai começando a entrar em um processo de desilusão e, nesse ponto, passam a ser criados os objetos transicionais e o espaço potencial (WINNICOTT, 1971a).

Winnicott (1971a) ressalta que o bebê busca uma área onde seja propiciado um alívio de tensão causado pela interação entre realidade externa e interna, e toda a turbulência emocional que o acompanha; assim, ele elege um objeto. Esse objeto é início de uma representação de algo que seja um "não-eu", surgindo um primeiro movimento de sair de si, mesmo que não diretamente ligado ao exterior. Portanto, o objeto transicional trata-se de uma área intermediária entre o bebê e o seio (mãe); ele está entre a criança e o mundo externo.

Winnicott (1971a) destaca que a transicionalidade é uma área de repouso psíquico do indivíduo, que está em função de manter a realidade interna e externa separadas, mas, ao mesmo tempo, inter-relacionadas. Todavia, não é sua função voltar-se totalmente ao mundo exterior e às suas exigências, como também não permite que o indivíduo se perca somente na sua realidade subjetiva. Considera-se que o objeto transicional (como algo concreto), com o passar do tempo, vai sendo menos necessário, restando o espaço entre a subjetividade e a objetividade, ou seja, as relações do indivíduo consigo mesmo, com os outros e com a realidade. O espaço potencial como esse "lugar simbólico" é especialmente rico, pois pode ser utilizado para fins criativos, compartilhados e que possam ser reconhecidos como legítimos no campo cultural, seja arte, religião ou filosofia, por exemplo (ABADI, 1998; SAMPAIO; BITTENCOURT, 2016; WINNICOTT, 1971a).

O mundo tão próximo e tão distante da literatura, nesse sentido, assume o papel de espaço potencial, já que acolhe a criatividade e as experiências criativas e de exploração e consegue promover ainda mais desenvolvimento, à medida que apresenta novos "outros", cria novos mundos, ressignifica e amplia os já existentes e permite a expressão livre dos sentimentos daquele que lê e do seu verdadeiro self (SAMPAIO; BITTENCOURT, 2016). Pensarmos em tais questões, como o amadurecimento psíquico e a expressão do verdadeiro self, por si só são representantes de saúde mental para o indivíduo. No entanto, tem-se considerado como a literatura pode ser utilizada como ferramenta terapêutica. 


\section{A literatura como ferramenta terapêutica}

Podemos dizer que a prática da literatura como ferramenta terapêutica data de longo período. No Antigo Egito, livros eram tratados como "remédios para a alma" e, na antiguidade grega e romana, foram associados a tratamentos médicos. Há relatos de a literatura ser utilizada de modo sistematizado e com caráter terapêutico propriamente dito na Segunda Guerra Mundial, quando surgiram, nos Estados Unidos, grupos de literatura terapêutica para soldados (ALONSO-ARÉVALO et al., 2018; VÉLEZ; PIETRO, 2018).

Tendo em vista os resultados positivos que a literatura proporciona, um elo mais estreito entre cuidado em saúde e literatura acabou sendo criado com vistas ao bem-estar da pessoa por meio da leitura. A isso foi dado o nome de "biblioterapia” (BORTOLIN; SILVA, 2016). Apesar de pouco difundidas e exploradas na atualidade, há iniciativas e programas que fomentam tal prática, seja como políticas públicas, seja em redes privadas, como vistas no Reino Unido, em Portugal, na Espanha e no Brasil, com aplicabilidades diversas, por exemplo, como suporte em período de hospitalização, fazendo a estadia ser mais amena; recomendação para pessoas em sofrimento mental; promoção de saúde para idosos institucionalizados, entre outros (FONSECA; AZEVEDO, 2016; BORTOLIN; SILVA, 2016; LEITE; CALDIN, 2017; VÉLEZ; PIETRO, 2018).

Consideramos que a literatura pode ser usada em associação com dispositivos médicos para o tratamento de ansiedade, de depressão, de transtorno obsessivo-compulsivo, de luto, para crianças lidarem com questões do seu desenvolvimento e prevenção de bullying, como também para adultos com dificuldades na relação conjugal, entre outros, com sua aplicabilidade sendo variada, em grupo ou individualmente, lendo ou ouvindo histórias (ALONSO-ARÉVALO et al., 2018; BORTOLIN; SILVA, 2016; VÉLEZ; PIETRO, 2018). Esses mesmos autores destacam que a literatura faz com que a pessoa esqueça momentaneamente a situação, o estado ou o momento no qual se encontra e abre a possibilidade para que esteja imersa em uma realidade diferente, promove a catarse e a ressignificação dos fatos.

No entanto, segundo Alonso-Arévalo et al. (2018), nem toda literatura seria para o "uso terapêutico”. Para sê-lo, inúmeros fatores devem ser considerados, como se há ou não enfermidade, condição sociocultural da pessoa ou grupo, a faixa etária, entre outros. É preciso que leve à reflexão do problema ao qual está inserida e não deve se tratar de uma literatura técnica, mas ser agradável e fácil.

A literatura também pode ser tomada como instrumento de prevenção de adoecimento e promoção de saúde, na medida em que, por meio dela, pode-se adquirir informações e conhecimentos. A literatura pode estimular o pensamento crítico, pode ser usada por simples diversão, para exercitar a imaginação e a criatividade, melhorar a memória, a empatia, o reconhecimento de emoções, a autorreflexão, para aliviar situações de forte mobilização emocional e fazer com que a pessoa se sinta mais positiva diante de seu cotidiano. Ao pensarmos a escrita, essas repercussões positivas também são válidas, uma vez que o ato de colocar no papel sensações e sentimentos é terapêutico por si só (ALONSO-ARÉVALO et al., 2018; FONSECA; AZEVEDO, 2016; OGUISSO; SILVA, 2017).

De modo a verificarem objetivamente o impacto positivo que a literatura pode ter na longevidade dos leitores, Bavishi, Slade e Levy (2016) desenvolveram um estudo ao longo de 20 anos, acompanhando 3.635 indivíduos com mais de 50 anos de idade. A cada dois anos, os 
pesquisadores faziam contato com esses leitores, questionando-os sobre os seus hábitos de saúde e de leitura. Em linhas gerais, constatou-se que houve maior mortalidade nos não-leitores de livros (33\%) em comparação aos leitores (27\%). Foi observado, também, que a leitura proporcionou uma sobrevida média de 23 meses nos leitores. No entanto, esses autores alertam que é importante considerar uma ampla gama de fatores que ajudam a expor esse panorama, como a existência ou não e o tipo de atividade laboral, a presença de doenças, o nível socioeconômico e até o estilo de vida; no entanto, considera-se que a leitura teve um papel de proteção à longevidade (BAVISHI; SLADE; LEVY, 2016).

Em que pesem esses resultados que sinalizam a potência terapêutica do emprego da literatura como um recurso em saúde, há de retomarmos que o seu resgate não pode se dar apenas como um elemento utilitário - no sentido de que se a literatura é essencialmente um recurso, este pode ou não ser empregado ou (contra)indicado. Este estudo compromete-se com uma leitura polissêmica, com a cura trabalhada para além do apascentamento, por exemplo. A literatura, assim, aproxima-se e alinha-se, em muitos momentos, a sentidos incômodos, desconfortáveis e que promovem mal-estar, permitindo a fruição de sensações que nem sempre são lícitas, por exemplo, em espaços que se propõem a promover a saúde. Ademais, permitir a escuta desses sentidos é também fundamental nesse diálogo.

Buscamos, neste estudo, fazer uma aproximação entre mundos, tal como visto anteriormente, distintos, mas que podem proporcionar uma confluência, a qual não deve estar comprometida com sentidos estanques e permanentes, mas em trânsito, em jogo. Talvez um terceiro espaço que não seja nem somente psicanálise e nem somente literatura, mas tenha potencial para a ação criativa, ainda que inicial, de um entusiasta de ambas as áreas, pois, como Leite (1987) coloca, a criação literária existiria independentemente das grandes narrativas que tentam explicar o mundo, como a Filosofia, a Sociologia, a Psicanálise e a Psicologia; mas não é totalmente avessa a isso. E como a psicanálise pode contribuir nesse processo?

\section{O saber psicanalítico e o seu encontro com a literatura}

Tradicionalmente, o saber psicanalítico tem sido associado a uma densa literatura construída no campo da saúde mental para pensar o tratamento de pessoas em sofrimento psíquico. Assim, por muito tempo, a psicanálise foi concebida como algo que só poderia se dar dentro de um determinado setting. Para além dessa leitura, há de compreendermos que o campo psicanalítico também se apresenta como método de investigação, como salientado por Safra (2013, p. 21), “para fora do consultório”. Por muito tempo, a tentativa de pensarmos a psicanálise para além do domínio do consultório foi definida como psicanálise aplicada, haja vista que seria impossível falarmos do inconsciente, por exemplo, fora da transferência no processo psicanalítico. Em que pesem as diversas críticas que se avolumaram nesse itinerário de uma psicanálise extramuros, Safra (2013) revela que, a partir da década de 1950, passou-se a pensar nas diversas possibilidades que emergiam ao pensarmos a linguagem e o texto para fora dos clássicos consultórios:

Na investigação, utilizando-se essa referência teórica podem-se observar as manifestações transferenciais e inconscientes no texto. Aqui estaríamos utilizando o método psicanalítico não só dentro do processo psicanalítico, mas 
também em outros fenômenos humanos mediados pela linguagem. Nas manifestações da linguagem, é possível investigar os fenômenos transferenciais como eles aparecem grafados no texto. Vemos o aparecimento de uma modalidade de investigação que irá estudar o discurso como fenômeno intersubjetivo e psicanalítico legítimo. [...]. Compreender o fenômeno intersubjetivo pela fala, texto ou discurso, ou abordar o fenômeno transferencial pela noção de campo, ou pela noção de espaço potencial, possibilitará o uso do método psicanalítico fora do consultório, em outros espaços para além do constituído no processo psicanalítico. (SAFRA, 2013, p. 22).

A partir dessas considerações, podemos dizer que a psicanálise também pode ser a condutora de um processo interpretativo que toma como fenômeno um texto literário. Segundo Leite (1987), é possível considerarmos a existência de níveis de compreensão até olhares diferentes a respeito de uma mesma obra, passando desde uma leitura superficial a explicações meta-psicológicas. Nesse sentido, uma perspectiva “adequada” pode enriquecer a compreensão e ampliar diálogos, ainda que, para tal, outros aspectos sejam parcialmente ignorados. Para aproximarmos a psicanálise e a literatura, priorizaremos o diálogo com o psicanalista D. W. Winnicott.

Winnicott nasceu em 1896, em Plymouth, na Inglaterra. Winnicott (2000) considera que, por volta dos seis meses de idade, já há uma vida mental muito intensa e importantes fatos para o desenvolvimento da personalidade do indivíduo já acontecerem. Em meio a esse processo de desenvolvimento e de desilusão, o bebê, para conseguir tolerar a frustração diante da ausência da mãe, para tranquilizar-se, uma vez que se vê a mercê de um turbilhão de sensações e demandas tanto internas quanto externas, elege um objeto para ser o substituto da mãe; trata-se do início de algo que seja externo a si; é no espaço de ausência que surge o objeto transicional (WINNICOTT, 1971a; OUTEIRAL, 2010).

Portanto, o objeto transicional, abordado anteriormente, trata-se de uma área intermediária entre o bebê e o seio, o qual está entre a criança e o mundo externo. O objeto transicional possibilita que seja elaborado o modo como se dará a relação de objeto subsequente. Há, nesse ponto, um paradoxo: a criança, pela onipotência inicial e necessária ao seu desenvolvimento, acredita ter criado o objeto, mas não foi uma criação pura. Por ter sido algo do mundo externo apresentado a ela e aceito, nem mesmo trata-se do próprio corpo dela, por isso, já há um fora; apesar de vir do mundo externo, passa pela subjetividade e pela criatividade e permite todas as manifestações emocionais (WINNICOTT, 1971a).

Acrescenta Abadi (2002) que o objeto transicional existe para receber as projeções do bebê e que, ao sobreviver a elas, ele adquire uma qualidade externa e de permanência, o que, por fim, diferencia-o de parte do ego do bebê; e aí estaria o cerne de uma relação de objeto. Nessa perspectiva, Winnicott (1971a) diz que o objeto transicional acaba sendo demasiadamente amado, acariciado, nutrindo-se grande afetividade por ele, como também deve ser capaz de suportar toda a gama de impulsos agressivos e destrutivos que o bebê apresentará. Nesse ponto, está a raiz do uso de um objeto (WINNICOTT, 1971b).

Outeiral (2010) ressalta que o importante, no que diz respeito ao objeto transicional, não é tanto o objeto em si, mas o uso que o bebê faz dele, a maneira como ele vai interagir e se continuará presente para o bebê, tanto que sua ausência também é amplamente sentida. Assim sendo, Winnicott (1971a) afirma que a transicionalidade é uma área de repouso psíquico do 
indivíduo, que está em função de manter a realidade interna e externa separadas, mas, ao mesmo tempo, inter-relacionadas. Assim, não é função da transicionalidade voltar-se totalmente ao mundo exterior e às suas exigências, como também não permite que o indivíduo se perca somente na sua realidade subjetiva.

Winnicott (1971a) diz que, no avançar do desenvolvimento saudável do bebê, ao conseguir lidar melhor com as falhas da mãe, é esperado que ele consiga deixar a ilusão onipotente de lado e perceber que a mãe "vai e volta”. Pode passar, portanto, a utilizar da sua atividade mental para lembrar-se e reviver, seja em fantasia, seja em sonho, e desenvolver uma integração temporal de passado, presente e futuro (realização). Nesse espaço é que se constrói o mundo interno do bebê, possibilitando a ele tornar-se ativo na busca de sua satisfação que pode acontecer de uma maneira mais desenvolvida e não alucinatória (onipotente), mas criativa; portanto, o objeto transicional concreto vai perdendo sua utilidade, sendo descatexizado e deixado de lado, pois cumpriu o seu papel no momento que se fazia necessário.

Agora o espaço entre subjetividade e objetividade pode ser utilizado para fins criativos, compartilhados e que possam ser reconhecidos como legítimos no campo cultural, pois a função da transicionalidade se amplia e abrange relações do indivíduo consigo mesmo, com os outros e com a realidade e, em última análise, a criança pode brincar (ABADI, 1998; WINNICOTT, 1971a). Destacamos, portanto, que o brincar está intimamente ligado aos objetos e aos fenômenos transicionais, repousando sobre o seu espaço potencial, sendo seu valor incomensurável, uma vez que brincar é verbo de ação e isso implica uma ação deliberada no mundo (WINNICOTT, 1971a, 1971c).

\section{Brincar com as palavras}

É no brincar que o contato do mundo interno com o externo pode ser sobreposto sem o temor de ser retaliado ou sofrer sanções. Nesse sentido, o espaço entre a subjetividade e a objetividade pode ser utilizado para fins criativos. Apenas no brincar que o ser humano pode usufruir da sua liberdade de criação. Esta seria, portanto, uma das principais atividades da vida do ser humano, podendo ser entendida como marcador de um desenvolvimento saudável. Na brincadeira, o que impera é a elaboração imaginativa e a comunicação estabelecida, mesmo que por meio de uma linguagem não verbal; isso pressupõe uma relação de objeto e de eu-outro, dando as bases para relacionamentos interpessoais e grupais (CICCONE, 2013; PÉRGOLA, 2019; WINNICOTT, 1971a, 1971c, 1971d). Consideramos, por conseguinte, que a brincadeira é uma das principais atividades da vida de qualquer indivíduo, tanto crianças como adultos, uma vez que só pode acontecer devido às experiências que favoreçam ao sujeito a sua existência, a sua continuidade e a sua criatividade, em um ambiente que acolha esse gesto espontâneo sem retaliação. O bebê sente-se protegido e a continuidade do seu ser é preservada pela possibilidade da exposição de si, configurando e fortalecendo o self, sendo a expressão máxima da criatividade de cada pessoa. O oposto disso, a não possibilidade da expressão criativa, um ambiente que não acolha ou invada o bebê, leva ao desenvolvimento de um falso-self, dado que ele se vê obrigado a ter de reagir a esse ambiente hostil para a preservação do seu núcleo, 
o que ocasiona implicações extremamente prejudiciais ao sujeito. O ser é diferente do reagir (CICCONE, 2013; WINNICOTT, 1971c, 1971d).

O reconhecimento da brincadeira e também a sua ausência na criança é algo nítido. No entanto, podemos considerar que a brincadeira também é uma atividade que deva ser observada nos adultos. Na vida adulta, o brincar envolve atividades compartilhadas e que possam ser reconhecidas como legítimas no campo cultural, em que se tem espaço para a expressão da criatividade, tal como na arte, na religião e na filosofia (WINNICOTT, 1971a, 1971c). Destacamos, portanto, que é com o brincar que a criatividade encontra vazão e é por meio da expressão da criatividade que o sujeito sente que a vida é digna de ser vivida. O contrário, como a submissão e a reação, remete ao sentido de inutilidade e, por consequência, não haveria sentido em viver (WINNICOTT, 1971e). Logo, para Winnicott (1971c), a função da psicanálise é resgatar a capacidade de brincar daquele que a perdeu bem como de auxiliá-lo na capacidade de usar objetos.

Como dito, se as experiências de brincar voltam-se ao campo cultural compartilhado, deste ponto em diante a atenção deve dirigir-se a um aspecto particular observado na obra de Winnicott: a sua relação do brincar com a literatura. A experiência cultural e artística são desdobramentos do brincar (LUZ, 2006). No entanto, essa comparação não é “inédita”. Freud (1996a) escreve, talvez, um dos mais importantes trabalhos no que se refere ao estudo de obras literárias segundo um olhar psicanalítico: trata-se do texto Escritores criativos e devaneios, publicado originalmente em 1908 e presente em suas Obras completas. França (2014) destaca que Freud era um forte apreciador de literatura e, com esse estudo, foi capaz de abrir um novo caminho não somente para a análise interpretativa e estética de obras literárias, mas também de compreensão para o funcionamento mental do ser humano.

A curiosidade a respeito da fonte de criatividade dos escritores é trazida para o centro da discussão, buscando uma compreensão pormenorizada. Ao adentrar o âmago de tal discussão, Freud (1996a) ressalta que explicações dadas pelos escritores em nada ajudarão no entendimento da sua capacidade criativa, uma vez que saber de tal fato de modo consciente não torna uma "pessoa comum” um artista, mas a reflexão se faria importante pois haveria um elemento comum a todos, que aproximaria essas duas “classes”.

Freud (1996a) propõe, assim, olhar para a atividade imaginativa da criança que brinca, em que ela reorganiza os elementos do seu mundo e cria enredos dos quais ela muito se ocupa e que lhes têm grande valor. Para ele, “[...] a antítese de brincar não é o que é sério, mas o que é real” (FREUD, 1996a, p. 135). O autor destaca, ainda, que a atividade livre e espontânea da criança tem em si um grande valor para a sanidade e, quando adultos, essa atividade deve encontrar outras maneiras de expressão, ainda que "brincando com as palavras" tal como o escritor que busca o viver criativo.

Cabe destacarmos a coerência de Winnicott, uma vez que, para ele, é necessária a existência de um mundo anterior para que haja a expressão da criatividade, visto que elementos pré-existentes servem como ponto de apoio para novas criações (PIRES, 2010). É possível notarmos que Winnicott pôde se beneficiar das propostas de Freud e fez ampliações muito criativas e importantes a esse respeito.

O espaço potencial tem grande valor na obra de Winnicott, pois este é o chão no qual se erguem as bases para a vida do ser humano expressos, principalmente, por intermédio de experiências culturais. Segundo Luz (2006), o espaço potencial é a área intermediária entre o 
eu e o mundo, possibilitando o encontro criativo do gesto espontâneo com o ambiente real. A criação literária ocorre nesse ponto, sendo possível "brincar” com os elementos do mundo real por meio da fantasia e da elaboração criativa (PIRES, 2010).

Winnicott entende que a fantasia está presente desde sempre na vida do ser humano e é a manifestação da criatividade de cada indivíduo que encontra expressão no mundo concreto. No entanto, a atividade de fantasiar pode expressar tensões existentes para o sujeito, colocando-se a serviço de uma força defensiva para lidar com a impotência, voltando-se para o seu interior e manipulando a realidade de forma onipotente. O contraponto disso é a elaboração imaginativa, sendo esta uma vertente saudável voltada a atividades criativas (PIRES, 2010). Destaca Winnicott (2000) que o problema da fantasia é que prevalece o pensamento mágico, e o amor e o ódio não conseguem ser freados, enquanto na realidade existem limites. $\mathrm{O}$ autor acrescenta que é possível adoecer aproximando-se tão somente de um mundo de fantasia sem ligação com o real. Do mesmo modo, permanecer preso à realidade, sem espaço para fantasiar, pode ser igualmente prejudicial.

Brincar com esses elementos, contudo, não é tarefa fácil. É preciso desenvolver a capacidade de usar objetos de modos mais adaptados (WINNICOTT, 1971b). Nesse processo, a pessoa depara-se com a grande desilusão de que os objetos estão fora do seu controle onipotente, já que eles são reais; no entanto, adquirem uma representação interna valiosa a cada indivíduo. Os impulsos destrutivos e o amor impiedoso do bebê encontram na realidade elementos que os barrem, observando que os objetos têm existência e significado independentemente dele próprio. Isso faz com que os objetos tenham valor para a criança e. assim, ela pode desenvolver a capacidade de manipulá-los e utilizá-los à medida que busca agir no mundo (WINNICOTT, 1971b).

Eis um limiar muito sutil entre as duas posições, do fantasiar onipotente e do fantasiar criativo. Esse é o terreno que o escritor caminha e, por isso, chama atenção a sua capacidade de brincar com as palavras, as quais são quase elementos vivos. A criação de suas narrativas é a brincadeira por excelência, de modo extremamente refinado. Usar a palavra é relacionar-se com elas, sujeitar-se à realidade limitante que elas impõem. O escritor as odeia e as ama. As palavras são do mundo real, não se sujeitam à vontade daquele que a manipula. Como não odiar? Todavia, o escritor, por ver que as palavras continuam a existir apesar do seu ódio, consegue amá-las e brincar com elas. Por seu amor, criar um mundo fantasioso, mas a serviço da realidade, o que lhe é libertador.

Diz Winnicott (2000, p. 226) que “[...] a criação artística aos poucos vai tomando o lugar do sonho, ou suplementando-o, sendo de importância vital para o bem-estar do indivíduo e, portanto, da humanidade”. É valioso usar a limitação em favor da expressão da liberdade, da criatividade, da possibilidade de existir e do bem comum. Segundo Leite (1987), a criação artística entraria justamente no ponto em que há a necessidade de lidar com questões emocionais que se tornam produtivas não só para a pessoa, mas a outrem.

Para Luz (2006), a poesia e a literatura formam uma comunicação especial, pois conduzem à realidade infinita de cada indivíduo. No entanto, este consegue adentrar o seu mundo interno sem sentir-se ameaçado com o que irá se deparar. É a capacidade de brincar e fantasiar com as palavras, reorganizando-as e as comunicando. A criação é um caminho sem fim, e seu valor está no trilhar. Nesse processo, fatalmente o sujeito acaba por deparar-se com “o estranho” que habita em si, podendo ser visto como algo tão novo e tão assustador, mas que sabe ser familiar 
(FREUD, 1996b). Na literatura, ao ecoar por esse espaço potencial, que se conduz para o encontro consigo mesmo, podendo haver estranhamento e reconhecimento, aversão e compaixão, repulsa e acolhimento, horror e encantamento, é o ser quem se é de modo verdadeiro, acolhendo-se por completo. É nessa possibilidade de expressão de si no real que se encontra o sentido que teria a vida (SAMPAIO; BITTENCOURT, 2016).

Na literatura estão presentes todos os aspectos vistos na atividade de brincar, como favorecer o desenvolvimento cognitivo e emocional; criam-se pontes entre diferentes pessoas (artista-leitor e entre leitores) com experiências de vida e visões de mundo distintas e aproxima essas pessoas à medida que conseguem reconhecer em si aspectos de semelhança. Para Winnicott (1971d), a psicanálise é o brincar junto do terapeuta com o paciente. Guardadas as devidas proporções e contextos, poderíamos considerar que a literatura é o brincar do autor com o leitor? A subjetividade do escritor que cria um mundo em suas histórias em conjunto com a literatura resgata no leitor a capacidade de fantasiar.

\section{Considerações finais}

A proposta de Winnicott é certa: viver de um modo criativo. À primeira vista pode parecer simplista. No entanto, o viver criativo que ele propõe é um resgate de si mesmo (CICCONE, 2013). Clarice Lispector muito sabiamente nos diz que o artista perfeito é aquele que consegue fazer um resgate à inocência criativa da criança e que fora perdida, libertando-se, fugindo das convenções e reafirmando a sua vocação pela liberdade (RUFINONI, 2016). O artista é o que esteve distante da inocência, entendida como o gesto espontâneo do bebê, e retornou, conseguindo transformar a sua realidade em obra; Winnicott, nessa linha, quase faria o convite à pessoa tornar-se artista.

A partir dos endereçamentos propostos neste estudo, concluímos com a necessidade de que as aproximações entre Psicologia e literatura, aqui costuradas sobretudo pelo viés da psicanálise e com foco na promoção de saúde, possam ter um espaço de maior destaque na literatura científica no campo da saúde mental. Compreendemos que esse diálogo não é algo novo, mas, muitas vezes, tem se apresentado apartado da formação em saúde que tem sido executada em nosso contexto, uma formação que, a despeito das rupturas sonhadas em relação ao modelo biomédico, ainda continua validando uma noção de sujeito fragmentado. Essa noção tem como consequência uma abordagem que distancia campos do conhecimento que também possuem como objetivo propor uma reflexão sobre o humano, como a literatura, priorizada nesta reflexão, e a arte de um modo geral. Propomos, dessa forma, que os aspectos aqui discutidos possam colocar-se a serviço não apenas de uma integração, mas de um resgate de saberes que sejam promotores de integração, de pertencimento e de um processo de maior humanização daqueles que promovem o cuidado. 


\section{Referências}

ABADI, S. Transições - o modelo terapêutico de Winnicott. São Paulo: Casa do Psicólogo, 1998.

ABADI, S. Explorações: perder-se e achar-se no espaço potencial. Revista Brasileira de Psicanálise, São Paulo, v. 36, n. 4, p. 807-816, 2002.

ALONSO-ARÉVALO, J. et al. La lectura y su relación con la salud y el bienestar de las personas. Revista Cubana de Información en ciencias de la Salud, La Habana, v. 29, n. 4, p. 1-12, 2018.

AZEVEDO, M. J. M. D. Psicanálise e criação literária. Revistas Portuguesa de Psicanálise, Porto, v. 39, n. 2, p. 75-79, 2019.

BAVISHI, A; SLADE, M. D; LEVY, B. R. A chapter a day: association of book reading with longevity. Social Science \& Medicine, [s. l.], v. 14, n. 1, p. 44-48, 2016. DOI: https://doi. org/10.1016/j.socscimed.2016.07.014

BORTOLIN, S; SILVA, S. D. Biblioterapia no âmbito hospitalar. Informação Profissões, Londrina, v. 5, n. 1, p. 52-74, 2016. DOI: http://dx.doi.org/10.5433/2317-4390.2016v5n1p52

CICCONE, S. D. Criatividade na Obra de D. W. Winnicott. 2013. 127 f. Dissertação (Mestrado em Psicologia como Profissão e Ciência) - Pontifícia Universidade Católica de Campinas, Campinas, 2013.

FONSECA, K. H. O.; AZEVEDO, F. Biblioterapia: relato de uma experiência no lar de idosos em Braga - Portugal. Revista ACB: Biblioteconomia em Santa Catarina, Florianópolis, v. 21, n. 2, p. 381-389, 2016.

FRANÇA, E. M. Psicanálise e literatura: Fundação e função. Remate de Males, Campinas, v. 34, n. 1, p. 263-282, 2014. DOI: https://doi.org/10.20396/remate.v34i1.8635846

FREUD, S. Escritores criativos e devaneios. In: FREUD, S. Obras psicológicas completas. Rio de Janeiro: Imago, 1996a. p. 131-143. (Edição Standard Brasileira). Obra original publicada em 1908.

FREUD, S. O “Estranho”. In: FREUD, S. Obras psicológicas completas. Rio de Janeiro: Imago, 1996b. v. XVII, p. 233-270. (Edição Standard Brasileira). Original publicado em 1919.

LAPLANCHE, J.; PONTALIS, J. B. Vocabulário da psicanálise. 4. ed. São Paulo: Martins Fontes, 2001.

LEITE, D. M. Psicologia e Literatura. São Paulo: Editora UNESP, 1987.

LEITE, M. B.; CALDIN, C. F. Programas de aplicação da biblioterapia no Reino Unido. Brazilian Journal of Information Studies: Research Trends, Marília, v. 11, n. 3, p. 53-65, 2017. DOI: https://doi.org/10.36311/1981-1640.2017.v11n3.06.p53 
LUZ, R. Winnicott: a poesia e a realidade. Natureza Humana, São Paulo, v. 8, n. 2, p. 315335, 2006.

MIYAGAWA, S.; LESURE, C.; NÓBREGA, V. A. Cross-Modality Information Transfer: a hypothesis about the relationship among prehistoric cave paintings, symbolic thinking, and the emergence of language. Frontiers in Psychology, [s. l.], v. 9, n. 115, p. 1-9, 2018. DOI: https://doi.org/10.3389/fpsyg.2018.00115

OGUISSO, T.; SILVA, O. Literatura y enfermería: fuentes y saberes para investigación em história. Cultura de los Cuidados, Alicante, n. 47, p. 129-148, 2017. DOI: https://doi. org/10.14198/cuid.2017.47.11

OUTEIRAL, J. O. Transicionalidade e criatividade: rabiscos sobre o viver criativo. Jornal de Psicanálise, São Paulo, v. 43, n. 78, p. 91-98, 2010.

PASSOS, C. R. P. Crítica literária e psicanálise: contribuições e limites. Literatura e Sociedade, São Paulo, v. 7, n. 6, p. 166-185, 2002. DOI: https://doi.org/10.11606/issn.22371184.v0i6p166-185

PÉRGOLA, M. C. O conceito de criatividade originária na obra de D. W. Winnicott. 2019. 112 f. Dissertação (Mestrado em Psicologia) - Instituto de Psicologia da Universidade de São Paulo, São Paulo, 2019.

PIRES, F. A. R. Criatividade no processo de amadurecimento em Winnicott. 2010. 89 f. Dissertação (Mestrado em Psicologia Clínica) - Pontifícia Universidade Católica de São Paulo, São Paulo, 2010.

RUFINONI, S. R. “O Artista Perfeito”: Clarice Lispector e a Poética da Inocência. Remate de Males, Campinas, v. 36, n. 2, p. 357-379, 2016. DOI: https://doi.org/10.20396/remate. v36i2.8647907

SAFRA, G. Investigação em psicanálise fora do consultório. In: SERRALHA, C. A.; SCORSOLINI-COMIN, F. (org.). Psicanálise e Universidade: um encontro na pesquisa. Curitiba: CRV, 2013. p. 19-26.

SAMPAIO, L. B. P.; BITTENCOURT, M. I. G. D. F. Psicanálise e literatura: Thomas Ogden e a poesia de Robert Frost. Subjetividades, Fortaleza, v. 16, n. 2, p. 71-82, 2016. DOI: https:// doi.org/10.5020/23590777.16.2.71-81

SANTOS, R. C. D.; SANTOS, J. C. D.; SILVA, J. A. D. Psicologia da literatura e psicologia na literatura. Temas em Psicologia, Ribeirão Preto, v. 26, n. 4, p. 767-780, 2018. DOI: https:// doi.org/10.9788/TP2018.2-09Pt

SCORSOLINI-COMIN, F. A infância clandestina em Clarice Lispector. Revista do SELL, Uberaba, v. 8, n. 2, p. 185-203, 2019. DOI: https://doi.org/10.18554/rs.v8i2.3936 
SCORSOLINI-COMIN, F.; FIGUEIREDO, I. A. Concepções de saúde, doença e cuidado em Primeiras estórias, de Guimarães Rosa. Saúde e Sociedade, São Paulo, v. 27, p. 883-897, 2018. DOI: https://doi.org/10.1590/s0104-12902018171009

SCORSOLINI-COMIN, F.; SANTOS, M. A. Todos passam pela via crucis: a corporeidade em Clarice Lispector. Psicologia em Estudo, Maringá, v. 15, n. 3, p. 623-632, 2010. DOI: https:// doi.org/10.1590/S1413-73722010000300020

SCORSOLINI-COMIN, F.; SANTOS, M. A. Família interdita: transgeracionalidade e subjetivação em três obras ficcionais. Psicologia em Estudo, Maringá, v. 17, n. 2, p. 255-266, 2012. DOI: https://doi.org/10.1590/S1413-73722012000200009

SILVEIRA, J. R. A. D. Arte e Ciência: uma reconexão entre as áreas. Ciência e Cultura, São Paulo, v. 70, n. 2, p. 23-25, 2018. DOI: https://doi.org/10.21800/2317-66602018000200009

VÉLEZ, I. B; PRIETO, J. L. La literatura como instrumento terapéutico en el proceso saludenfermedad durante la infancia. Enfermería Global, Murcia, v. 17, n. 50, p. 585-616, 2018. DOI: https://doi.org/10.6018/eglobal.17.2.299201

WINNICOTT, D. W. Desenvolvimento emocional primitivo. In: WINNICOTT, D. W. Da pediatria à psicanálise - Obras escolhidas. 2. ed. Rio de Janeiro: Imago, 2000. p. 218-233.

WINNICOTT, D. W. Objetos transicionais e fenômenos transicionais. In: WINNICOTT, D. W. O brincar e a realidade. Imago: São Paulo, 1971a. p. 13-44.

WINNICOTT, D. W. O uso de um objeto e relacionamento através de identificações. In: WINNICOTT, D. W. O brincar e a realidade. Imago: São Paulo, 1971b. p. 121-131.

WINNICOTT, D. W. O brincar: uma exposição teórica. In: WINNICOTT, D. W. O brincar e a realidade. Imago: São Paulo, 1971c. p. 59-77.

WINNICOTT, D. W. O brincar: a atividade criativa e a busca do Eu (Self). In: WINNICOTT, D. W. O brincar e a realidade. Imago: São Paulo, 1971d. p. 79-93.

WINNICOTT, D. W. A criatividade e suas origens. In: WINNICOTT, D. W. O brincar e a realidade. Imago: São Paulo, 1971e. p. 95-120. 